\title{
THE COUNTRYSIDE IN 1970
}

\author{
By E. M. NICHOLSON, C.B. \\ Director-General, The Nature Conservancy, 19 Belgrave Square, London, S.W.I
}

\begin{abstract}
CONFERENCES nowadays follow one another so $A$ rapidly that those most involved in them may find it hardest to assess their real objectives in relation to what they actually do and what, if any, further results flow from them. Yet the fact that conferences monopolize so much time of busy people and cost so much to organize and attend casts a moral obligation on their promoters not only to see that these resources are well spent, but also to provide their quota towards the necessary data for developing the science and art of holding conferences, as well as towards whatever may be the subject-matter of their own exercise. This is borne in mind in the following discussion of the Duke of Edinburgh's Second Study Conference on "The Countryside in 1970", held in London during November 10-12, 1965.

Conflicts between developers accused of despoiling the countryside and champions of its preservation go back at least to Wordsworth, and arguably to John Evelyn, who succeeded three centuries ago in promoting what would now be termed a highly successful conservation campaign against the ironmasters who were laying waste the English woodlands. Thus vanquished, they found necessity the mother of invention to the extent of devising means of substituting coal for charcoal and thus, undor conservationist pressure, finding the way to creating the steel industry. During the nineteenth century, however, development in its crudest forms was increasingly permitted, and the well-meaning voluntary bodies formed to combat such tendencies never won enough support or attained enough cohesion to reverse the trend. This was dramatically shown in the main London exhibition for National Nature Week in 1963. Following a visit to the exhibition the Duke of Edinburgh resolved to bring the parties together at a study conference in the autumn of 1963 to seek a means of agreeing on both a diagnosis and an approach to a remedy before, as he feared, the national inheritance in the countryside became irrevocably damaged by about 1970 .
\end{abstract}

Hurriedly improvised and patchily documented, the 1963 Conference was nevertheless judged a considerable success. It brought together representatives, mainly at a high level, of some ninety national organizations including Government departments and public concerns, professions, scientific and technical organizations, and bodies representative of industry, agriculture, landowning, recreation, natural history, amenity and other interests concerned.

Many of these were hitherto scarcely aware of the existence of one another, and it proved a revelation for them to meet face to face in the three large working parties and to begin to learn of their respective aims, problems, policies and points of view. By the time the Conference ended, it had initiated many fruitful contacts, harnessed much vague goodwill into a definite, if frankly empirical, common movement embracing hitherto conflicting parties, and prepared the way for a more scientific and educational treatment of the whole vast complex of problems.

Such treatment was facilitated by a contribution from the Nature Conservancy of a chart of "Human Impacts on the Countryside", prepared by A. W. Colling and myself. This chart listed and analysed the incidence and effects of all traceable activities and operations (numbering more than 160) involving distinguishable types of impact by a human group or organization on the country- side. The Conference directed much attention to requirements in terms of research and investigation leading to a better understanding of the problems. Following publication of the Proceedings of the Study Conference (H.M.S.O., 1964), an exhaustive analysis was made of all the suggestions, and recommendations for action or for further study. Three follow-up conferences were arranged, on "Agricultural Chemicals-Progress in Safe Use" held in London in March 1964, on Scottish aspects held at Inverness in April 1964, and on educational aspects at the University of Keele in March 1965. Special account was also taken of a number of allied projects, including the National Trust's "Enterprise Neptune" for saving key areas of coastline, the Nature Conservancy working party and report on "Broadland", tho Civic Trust's recreational plan for the Lea Valley, and the Nuffield-Cambridge survey of common lands.

While these conferences and projects contributed encouragingly towards giving practical shape to the ideas outlined in November 1963, it was felt that a renewed effort in more depth was needed. This took the form of a second conference, two years after the first, prepared by twelve study groups working intensively within four broad areas; legislation and administration; users and uses of the countryside; technology and impacts on land; oducation, training and qualifications; and information.

With the formation of these study groups a new departure began, since their terms of reference were based on needs brought to light by the first conference, whilo their membership included more than 180 men and women selected partly for their specialized knowledge and partly for their close association with a wide range of bodies most intimately and continuously concerned. Each study group was serviced by a different organization, official or unofficial, including the National Parks Commission $(4$, countryside: planning practice); the Scottish Development Department (9, countryside: planning and development in Scotland); the Forestry Commission (3, technology in conservation); the National Coal Board (12, reclamation and clearance of derelict land); the Lincolnshire (parts of Lindsey) County Counoil (8, preservation of natural, historic and other treasures); the Town Planning Institute (1, training and qualifications of planners); the Royal Institute of Chartered Surveyors (2, training and qualifications of the professions concerned with land and water); the Council for Nature (5, review of legislation); the National Council of Social Service (11, living and working in the countryside); the Automobile Association (7, traffic and its impact on the countryside); the National Benzole Co., Ltd. (10, information and the countryside).

All these study groups worked simultaneously to complete their reports by July 1965. Their devoted chairmen and convener secretaries formed, together with the organizing committee of vice-presidents, sessional chairmen, joint secretaries and others, a central steering group, served administratively by the Royal Society of Arts and on matters of programme and content by the Nature Conservancy. Thus, of about 360 who participated in the final plenary sessions of the second conference, some 50 had actively assisted in its organization, and nearly 150 more had worked on the preparatory study groups from many different points of view, and had taken part in the lively and critical review of the findings as a 
whole during the first two days (November 10 and 11). It appeared, as was to be expected, that this stiffening of seasoned members gave the eventual conference a markedly greater depth, cohesion and focus than that held in 1963, when the majority came new to the subject and to one another.

It had been expected that some study groups would not merely overlap in their coverage, as they rightly did, but would reach conflicting or inconsistent findings, which, with negligible exceptions, they did not. The difficulties which occupied the conference were of a different order, arising from differences in underlying assumptions or emphasis regarding the right scope of the enquiry and the true importance of different elements or interests. Differences also arose regarding the means of fulfilling aims on which all were broadly agreed, and the safeguards for other national or sectional interests affected.

Originally it had seemed that the most urgent and intractable problems might be to resolve differences between voluntary bodies within the naturalist and conservation. movement, and between that movement and its potential allies in recreation and among the other 'guardians of amenity', so as to enable the 'conservationists' to speak with one voice to the 'developers'. This presupposed that the 'developers' themselves would become familiar with the issues and be organized not only to express views but also to be able to play an active part in improving liaison, planning machinery and procedures, so as to transform the often negative and time-wasting encounters into a positive and constructive process of reconciling, so far as practicable, conservation with dovelopment.

Somewhat surprisingly, it seemed, subject to later confirmation, that these difficulties had been overrated. Since, and no doubt partly owing to, the first conference, it had become fashionable to pay a good deal more than mere lip-service to the overriding need for rapid joint action, and many good examples became manifest. These included the voluntary agreement for withdrawal of toxic chemicals known to be injurious to wild life under certain conditions; the joint policies and practices agreed on by the Forestry Commission; the National Parks Commission and the Nature Conservancy; the surprising unanimity reached by authorities and interests concerned with the Lea Valley and the Norfolk Broads; the progressive outlook of the 'land-linked professions' revealed in Study Group 2; and the almost universal welcome for a broad-based 'Countryside Commission'. The merger of representative bodies for employers and industry in the new Confederation of British Industry opened fresh possibilities of liaison. There was also a marked and most welcome growth in the readiness of planners and planning authorities to envisage substantial changes.

Welcome as were these and other signs of probable progress, they were still outnumbered and outweighed by more adverse factors. The new Regional Boards, too lately constituted to be reliably evaluated yet, were clearly liable to exercise great influence over large-scale development which could fail to take adequate account of the findings of the conference. Nationally it was clear that, in the absence of such impetus as the conference provided, recent tendencies to neglect countryside factors and interests in national planning wore likely to continue. It seemed misguided on this basis to argue, as some did, that the scope should be widened to include the whole of urbaniza. tion and town planning, the effect of which could only be to relegate countryside problems and interests to a minor place in the only effective forum available to them. On the other flank some, although by no means all, spokesmen of country-dwellers and rural occupations adopted an attitudo by no means consistent with the growing trends and impacts, which they seemed to underrate or misunderstand, and which called for much moro energetic and thoughtful efforts on their part to reach a new modus vivendi with the towns and their recreational, technological and accommodation pressures before it is too late. While it is only too easy to attract letters to the editor and impromptu speeches and articles from the angle of the country-dweller, there seems to be a severe dearth of thorough study and critical thought by countrydwellers themselves about present-day and impending impacts on the countryside. While this situation persists it helps no one to coin slighting deseriptions of academic and other contributors who try, as best they can, to throw some light on these dangerously neglected problems.

Another problem area in this regard is education, and some feeling was aroused by the suggestion that the educational world had not been approached to participate, or that it had been approached in the wrong way. In fact, although every other major national interest approached, from administration (national and local) and angling to women's institutes and youth hostels, responded to the call, it proved impossible, even with patient, tactful and persistent efforts in many quarters, to obtain leading ropresentatives of the teachers who bear so great a responsibility and dispose of such great resources and potentialities regarding the future of the countryside. It is to be hoped that the leaders of this great profession. will soon awaken, and that meanwhile they will discourage suggestions that their help has not been invited, which are very far from the truth. Meanwhile, fortunately, such bodies as the Field Studies Council and a number of local education authorities and training colleges are demonstrating how much can be done where the vision and the will exist.

Among problems which remain to be seriously faced are the study of resource economics, including the adequate development of cost/benefit analysis in relation to recreational uses, the future relation of industry to the countryside, tourism in relation to domestic, educational and recreational policies, and the implications of a national land-use policy based on multi-purpose use and zoning principles. Others include land requirements for defence purposes and the role of research in both the natural and the social sciences on human impacts on the natural environment. It is to be hoped that the Natural Environment Research Council and the Social Sciences Research Council will be able to stimulate more adequate work in these fields.

So far as practicable, the Countryside Conferences have been based on assembly of data from research and investigations, supplemented by fresh work wherever time and resources permit, and brought into focus on emerging problems as a basis for the disciplined discussion of the issues and of possible recommendations by selected groups deliberately drawn from a wide range of professions and interests. Much of the knowledge used was either new, unused or under-used proviously, and it therefore led to an unexpectedly wide and rapid advance in understanding of the problems. For example, the report of Study Group 3 assembles a range of selected factors in technology relevant to the countrysido which make possible a new and more comprehensive view of modern environmental management. Not only the results of the Conference, but the means by which they were reached, will repay investi. gation.

No othor country has yet attempted such an approach. The nearest has been President Johnson's White House conference on "Natural Beauty" in May 1965, but this, although most impressive of its kind, was very lightly documented and was preoccupied with urgent legislation and administrative action, much of which has long been taken in Britain. It is, however, to be borne in mind that documentation on such aspects as recreational pressures and water resources is vastly fuller and more advanced in the United States than in Britain. There is, however, no scientific organization elsewhere in the world looking systematically at problems of the natural environment and the impact of man on it. Without such a basis any. thing quite like the conferences on "The Countryside in $1970^{\prime \prime}$ would not be possible. 